Sharif University of Technology
Scientia Iranica
SCIENTIA
I RAN ICA
http://scientiairanica.sharif.edu

\title{
Modeling concrete thermal expansion based on packing density theory
}

\author{
M.A. Etebari Ghasbeh, P. Ghoddousi, and A.A. Shirzadi Javid* \\ School of Civil Engineering, Iran University of Science and Technology, Narmak, Tehran, P.O. Box 16765-163, Iran.
}

Received 4 June 2020; received in revised form 19 November 2020; accepted 4 January 2021

\author{
KEYWORDS \\ Coefficient of Thermal \\ Expansion (CTE); \\ Supplementary \\ cementitious \\ materials; \\ Packing density; \\ Prediction; \\ Concrete; \\ Cement paste.
}

\begin{abstract}
This study investigated the effects of supplementary cementitious materials with changes to the structure of the concrete pores based on Coefficient of Thermal Expansion (CTE) at different ages. The results indicated a descending trend for the CTE of the reference concrete up to 60 days (decreasing by about 12\%), after which it remained constant. On the contrary, a different trend was observed for the slag-containing concrete; in other words, the descending trend started after 60 days and its CTE declined by $10 \%$ up to 120 days. In the following, two equations for the concrete were presented to estimate its CTE during its lifetime based on its CTE at the age of seven days. In all concretes, the CTE reduction was associated with the reduced porosity. Moreover, the results of evaluating the pore size distribution showed that with a decrease in the pore diameter, the CTE decreased as well, indicating a strong relationship between the median diameter of the pores and the CTE. Given that the CTE depends on the aggregates and cement paste, a model was proposed based on the CTE of the cement paste and its packing density to estimate the CTE of the concrete.

(C) 2021 Sharif University of Technology. All rights reserved.
\end{abstract}

\section{Introduction}

Concrete structures are exposed to thermal changes due to diurnal changes and seasonal variations throughout their lifetime. These thermal changes can affect concrete properties. Like any other material, concrete undergoes volume changes in response to thermal changes. In some structures such as concrete pavements or bridges whose length is larger than width and height, these volume changes are regarded as length variations. Such alterations per a unit degree of thermal difference are called the linear Coefficient of Thermal Expansion (CTE). Since such length alterations

\footnotetext{
*. Corresponding author.

E-mail addresses: mohammadali_etebari@yahoo.com (M.A. Etebari Ghasbeh); ghoddousi@iust.ac.ir (P. Ghoddousi); shirzad@iust.ac.ir (A.A. Shirzadi Javid)
}

are minor, this coefficient is represented on a micro scale. Evaluation of the CTE points to the increased extent of cracks and damage to the concrete pavement. To be specific, with an increase in the CTE from 9.5 to 11 micro strain per degree centigrade, there was a $20 \%$ increase in the extent of concrete pavement cracks [1]. Moreover, such increases in cracking and faulting distress are associated with increase in CTE [2]. Among all types of cracks, transverse cracking is most affected upon an increase in the CTE of the pavement concrete [3]. In addition, curling stresses may occur as a result of temperature differences in the thickness of the concrete slab [4]. AASHTO T336-11 [5] presented a standard for measuring the CTE of a concrete, known as cylindrical sample length changes with concrete temperature variations inside a water basin between 10 and $50^{\circ} \mathrm{C}$. Furthermore, TI-B 101 [6] presented a method for measuring the CTE of a prismatic sample with thermal changes between 5 and $35^{\circ} \mathrm{C}$.

Since concrete is a composite body, its behavior 
is similar to that of its constituents. In addition, since the volume of the aggregates in the concrete is greater, the CTE of the aggregates has a major effect on that of the concrete. In particular, coarse aggregates can affect the CTE of the concrete more significantly than fine aggregates [7]. Compared to calcareous aggregates, siliceous ones can increase the CTE of the concrete up to $30 \%[8,9]$. Furthermore, the ratio of the coarse aggregate in the total aggregate content affects the CTE of the concrete such that upon an increase in this ratio, the CTE of the concrete would decrease [10]. In addition to aggregates, cement paste affects the CTE of the concrete. The humidity percentage for the cement paste has a significant effect on its CTE [11-13] such that it reaches its the maximum value at a humidity rate of $70 \%$ and its minimum in the dry state. To some extent, the CTE value in the saturation state is larger than that in the dry state [14]. Research findings revealed that the CTE of the cement paste was twice as large as that of the aggregate, thus making micro cracks in the boundary between the aggregates and the paste in the concrete. After 120 temperature cycles, the compressive strength of the concrete drops by $30 \%$ [15]. Accordingly, a reduction in the CTE of the cement paste can considerably improve the concrete quality. The most significant factors affecting the CTE of the cement paste are solid materials, water, and pores inside the cement paste [16].

According to Darwin et al. [17], porosity inside the concrete can be categorized into three main types: gel pores (smaller than $10 \mathrm{~nm}$ ), small capillary pores $(10-50 \mathrm{~nm})$, and large capillary pores $(50-1000 \mathrm{~nm})$. Extensive research has recently investigated the effects of supplementary cementitious materials, such as metakaolin and silica fume, on the total porosity of the cement paste and concrete. However, the obtained results were contradictory in terms of the reduction or elevation of total porosity [18-20]. Through the pozzolanic reaction, supplementary cementitious materials cause changes in the porosity of the concrete. Different effects of pozzolanic reactions were observed in terms of time. Li et al. [21] added slag and fly ash to cement paste and observed enhanced total porosity at an early age. With further aging and pozzolanic reaction, after 28 days, they observed a reduction in the total porosity of the samples containing supplementary cementitious materials, compared to the reference sample. Similarly, Divsholi et al. [22] added slag to cement paste and found enhanced total porosity and diminished pores. Furthermore, Pandey and Sharma [23] reported elevated total porosity resulting from incorporation of slag and fly ash to cement mortars at an early age. Poon et al. [24] added fly ash, metakaolin, and silica fume to concrete and examined the structure of its pores. They found that incorporation of all supplementary cementitious materials caused changes to the structure of the concrete pores, i.e., the pores shrank in response to these additions. Sullivan et al. [25] found that the simultaneous use of slag and metakaolin had a better effect on reducing the CTE of the concrete than incorporating them alone.

The $W / C$ ratio was found to be very effective in the CTE of the concrete; in other words, upon increasing the $W / C$ ratio, the CTE of the concrete would increase [26]. Changes in the structure of the cement paste pores would consequently change its CTE value. Shui et al. [27] incorporated fly ash and slag into the cement paste and observed variations in both porosity and CTE of the paste. While increasing the amount of fly ash and slag would increase the porosity, increasing the silica fume would decrease it. They concluded that the smaller size of the silica fume than the cement that improved the rate of cement hydration and the slowness of the pozzolanic reaction of fly ash and slag were the main reasons behind the above finding. On the contrary, upon increasing the porosity in the paste containing fly ash and slag, the CTE of the paste would decrease, and increasing the porosity in the paste containing silica fume would increase the CTE. Moreover, Gao et al. [28] incorporated fly ash to concrete and concluded that it could significantly reduce the CTE in the cement. However, addition of the slag resulted in growth at an early age. In addition, as the age of the samples increased, their CTE decreased; further, the reduction in the concrete containing slag was greater than that of the reference concrete. However, at the age of 50 days, the reduction values became almost equal, where the minimum level of reduction was observed for the concrete containing fly ash. A number of other research studies have also explored the effects of the sample age on the CTE. For instance, Won [10] measured the CTE up to the age of 22 days and found it constant. In another study, Alungbe et al. [29] evaluated the CTE of concretes made of three types of aggregates and three different values for the cement content at different water-tocement ratios. By measuring the CTE of the concrete in the saturation state, the equality of CTE of the concrete at the ages of 28 and 90 days observed for all the samples.

The effects of supplementary cementitious materials on the compressive strength, porosity, porosity structure of the concrete, and cement paste have been investigated in different studies. Supplementary cementitious materials perform pozzolanic reactions and change the physiochemical structure of the cement paste and transition zone between the paste and aggregates in the concrete, thus improving the mechanical properties and durability of the concrete [30-34]. However, supplementary cementitious materials cause changes in the packing density of the concrete since they are of higher quality than the concrete. Appli- 
cation of finer cement or supplementary cementitious materials, with a smaller size than cement, would yield reduced packing density in the concrete $[35,36]$.

\section{Research significance}

The present study aims to investigate the effects of cement paste on the CTE of the concrete. To this end, the course of changes in the porosity of the concrete and paste as a result of hydration and pozzolanic reactions was evaluated when introducing silica fume, metakaolin, and slag to the concrete and the cement paste and monitoring the CTE variations in the concrete and the paste over time. Moreover, in order to predict the CTE of the concrete at different ages, a model was proposed for the concrete with and without supplementary cementitious materials based on its CTE at the age of seven days. Through this model, the CTE of the concrete can be predicted at the desired age. To do so, mixtures of concrete and paste without supplementary cementitious materials and those containing silica fume, metakaolin, silica fume and metakaolin, and slag were examined from the age of 7 to 120 days. In addition, the size distribution of the concrete pores was measured to analyze the relationship between the size of the pores and CTE of the concrete. Finally, to predict the CTE of the concrete, a model was presented based on the packing density and the CTE of the corresponding concrete.

\section{Experimental design}

\subsection{Materials}

In this study, type-II cement with a density of $3150 \mathrm{~kg} / \mathrm{m}^{3}$ that was measured according to the ASTM C188 Standard [37] was employed. The supplementary cementitious materials used in this study included silica fume with a density of $2200 \mathrm{~kg} / \mathrm{m}^{3}$, metakaolin with a density of $2500 \mathrm{~kg} / \mathrm{m}^{3}$, and blast-furnace slag with a density of $2700 \mathrm{~kg} / \mathrm{m}^{3}$. The chemical properties of the

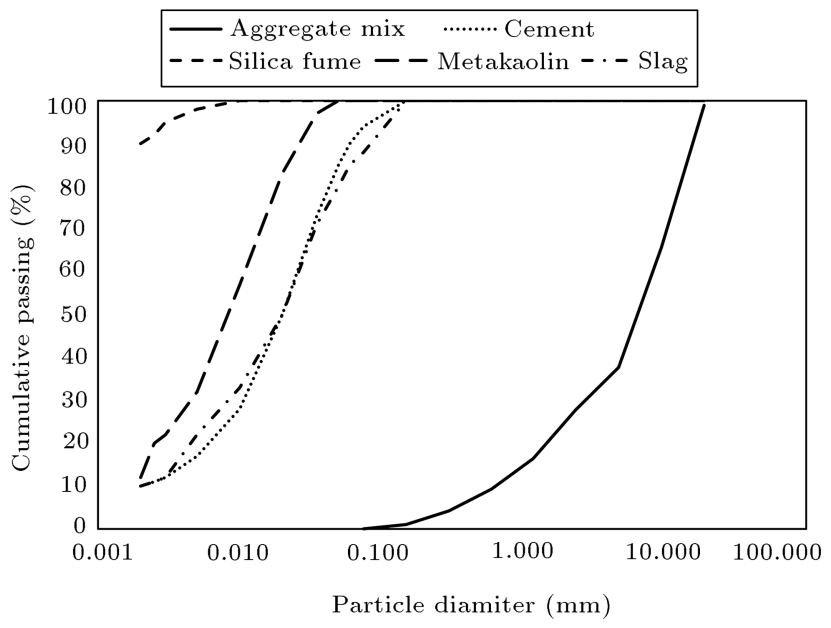

Figure 1. Particle size distribution of cementitious materials and aggregate.

cement and supplementary cementitious materials are presented in Table 1.

In addition, the type of aggregate is limestone. Figure 1 shows the particle size distribution of the cementitious material (i.e., cement, silica fume, metakaolin, and slag) and aggregate.

\subsection{Preparing the concrete and the cement paste samples}

In this study, five different concrete mixtures including RC, C-SF, C-MK, C-SF-MK, and C-SL were used that represented the reference concrete, concrete containing silica fume, concrete containing metakaolin, concrete containing silica fume and metakaolin, and concrete mixture containing slag, respectively. Furthermore, five paste mixtures, i.e., the combination of water and cement materials without any aggregates, were synthesized in proportion with every concrete sample with the same water-to-cement ratio and the same content ratio for the supplementary cementitious materials. The water-to-cement materials ratio across all the concrete and paste samples was set to 0.45 . Moreover, the

Table 1. Chemical compositions of cement and supplementary cementitious materials.

\begin{tabular}{ccccc}
\hline $\begin{array}{c}\text { Chemical composition } \\
\text { (weight \%) }\end{array}$ & \multicolumn{4}{c}{ Material } \\
\cline { 2 - 5 } & Cement & Silica fume & Metakaolin & Slag \\
\hline $\mathrm{SiO}_{2}$ & 20.74 & 94 & 75.29 & 34.91 \\
$\mathrm{Al}_{2} \mathrm{O}_{3}$ & 4.9 & 1 & 17.03 & 13.36 \\
$\mathrm{Fe}_{2} \mathrm{O}_{3}$ & 3.5 & 0.1 & 0.54 & 0.54 \\
$\mathrm{CaO}$ & 62.95 & 1 & 1.34 & 37.57 \\
$\mathrm{MgO}$ & 1.2 & 0.6 & 0.7 & 5.2 \\
$\mathrm{SO}_{3}$ & 3 & 1.2 & - & 3.46 \\
$\mathrm{Na}_{2} \mathrm{O}$ & 0.47 & 0.3 & 2.26 & 1.1 \\
$\mathrm{~K}_{2} \mathrm{O}$ & 0.58 & 0.37 & 0.84 & 1.1 \\
\hline
\end{tabular}


Table 2. The mixture proportions of concrete.

\begin{tabular}{cccccccccc}
\hline & \multicolumn{7}{c}{ Material $\mathbf{( k g / \mathbf { m } ^ { 3 } )}$} \\
\cline { 2 - 8 } $\begin{array}{c}\text { Specimen } \\
\text { notation }\end{array}$ & W/C & Binder & Cement & $\begin{array}{c}\text { Silica } \\
\text { fume }\end{array}$ & Metakaolin & Slag & $\begin{array}{c}\text { Course } \\
\text { aggregate }\end{array}$ & $\begin{array}{c}\text { Fine } \\
\text { aggregate }\end{array}$ & Slump (mm) \\
\hline RC & 0.45 & 400 & 400 & 0 & 0 & 0 & 1053 & 702 & 60 \\
C-SF & 0.45 & 400 & 368 & 32 & 0 & 0 & 1043 & 698 & 45 \\
C-MK & 0.45 & 400 & 320 & 0 & 80 & 0 & 1043 & 695 & 60 \\
C-SF-MK & 0.45 & 400 & 288 & 32 & 80 & 0 & 1036 & 691 & 40 \\
C-SL & 0.45 & 400 & 200 & 0 & 0 & 200 & 1037 & 691 & 70 \\
\hline
\end{tabular}

content of the cement materials in the concrete samples was set to $400 \mathrm{~kg} / \mathrm{m}^{3}$. After synthesis, all samples were wetted for $24 \mathrm{~h}$ in a gunny sack. Then, the samples were cured in saturated slacked lime basins at $21^{\circ} \mathrm{C}$ until reaching the desired test age. The mixture ratios in the concrete are provided in Table 2. To prevent flocculation of silica fume when mixing the concrete as well as the heterogeneity of the concrete mixture, the material was poured into mixed water before its addition to the concrete mixture. Once the silica fume and water mixture were prepared and the silica fume gel was formed, the gel was added to other materials in the concrete inside a mixer.

\subsection{Tests}

3.3.1. Porosity and compressive strength

To measure the porosity, the ASTM C642 Standard [38] was employed. According to this standard, the weight of the samples was measured after drying them in the oven for the desired duration $(A)$. Once the sample was cooled off in the open air, it was placed inside a water basin for at least $24 \mathrm{~h}$. After complete saturation, the sample was placed in the boiling water and after $5 \mathrm{~h}$, the saturated weight with the dry surface of the sample was measured $(B)$. Then, the weight of the sample was measured as a floating state $(C)$, and the porosity of the sample was calculated based on Eq. (1). Of note, while cubic samples of $10 \times 10 \times 10 \mathrm{~cm}$ in size were used for the concrete, samples of $5 \times 5 \times 5 \mathrm{~cm}$ in size were used for the paste. This test was performed at the ages of $7,28,56$, and 120 days:

Volume of permeable porespace $=\frac{(B-A)}{(B-C)} \times 100$.

After measuring the porosity, the compressive strength test was performed on the samples.

\subsubsection{The water absorption test}

The ASTM C642 Standard [38] was employed to measure the water absorption. The weight of the sample was measured based on this standard and after drying it in an oven $(A)$. Then, the sample was placed inside the water basin for at least $24 \mathrm{~h}$ and the saturated weight with the dry surface of the sample was measured
$(B)$. Next, the sample was placed in the boiling water and after $5 \mathrm{~h}$, the saturated weight with the dry surface of the sample was measured again $(C)$. Next, the weight of the sample was measured as a floating state $(D)$. Water absorption and volume of permeable pore space of the sample were calculated using Eqs. (2) and (3), respectively. It is worth mentioning that cubic samples of $10 \times 10 \times 10 \mathrm{~cm}$ in size were used for the concrete, while those of $5 \times 5 \times 5 \mathrm{~cm}$ in size were used for the paste. This test was performed at the age of 7 , 28,56 , and 120 days.

$$
\begin{aligned}
& \text { Water absorption }=\frac{(B-A)}{A} \times 100 \\
& \text { Volume of permeable porespace }=\frac{(C-A)}{(C-D)} \times 100 .
\end{aligned}
$$

\subsubsection{Mercury Intrusion Porosimetry (MIP)}

To examine the effects of the size distribution of porosity on the thermal expansion, the concrete samples of $5 \mathrm{~mm}$ containing no coarse-grained particles were separated at the age of 28 days, to which MIP was applied. Prior to the test, the samples were dried in an oven for $24 \mathrm{~h}$ at $105^{\circ} \mathrm{C}$ and were kept in a desiccator until the experiment. In this experiment, the pores with sizes between 10 and $1000 \mathrm{~nm}$ were accessible.

\subsubsection{Measurement of packing density}

In order to calculate the packing density of the concrete mixtures, the method presented by Wong and Kwan [36], known as the wet method, was employed. According to this method, after mixing the concrete components, the concrete is poured into a cylindrical container with a specific volume in three layers and then, it is smashed. Once the container is completely filled, its weight is measured and the weight of the concrete inside the container is recorded. Afterward, the density and volume of the constituent materials of the concrete are utilized to calculate the concrete packing density based on Eqs. (3) and (4):

$$
V_{c}=\frac{M}{\rho_{w} u_{w}+\rho_{g} R_{g}+\rho_{s} R_{s}+\rho_{c} R_{c}+\rho_{m} R_{m}},
$$

where $M$ represents the weight of the concrete, $\rho_{w}$ 
and $u_{w}$ are the density and ratio of the volume of the water to that of the solid grains, respectively. Moreover, $\rho_{g}, \rho_{s}, \rho_{c}$, and $\rho_{m}$ denote the density of the gravel, sand, cement, and supplementary cementitious materials, respectively. Furthermore, $R_{g}, R_{s}, R_{c}$, and $R_{m}$ represent the volumetric ratios of the gravel, sand, cement, and supplementary cementitious materials to the total volume of the solid grains inside the concrete, respectively.

Finally, after obtaining the volume of the concrete $(V)$ and $V_{c}$, we can calculate the packing density $(\phi)$ using Eq. (5):

$$
\phi=\frac{V_{c}}{V} \text {. }
$$

\subsubsection{The thermal expansion coefficient}

The thermal expansion coefficient of the concrete and paste samples was measured according to the TI-B 101 Standard. To measure the thermal expansion coefficient of every concrete mixture, two prismatic samples with dimensions of $10 \times 10 \times 40 \mathrm{~cm}$ were synthesized; however, two prismatic samples with dimensions of $2.5 \times 2.5 \times 28 \mathrm{~cm}$ were prepared for the cement paste Then, the thermal expansion coefficient of the samples was measured from the age of seven days up to 120 days at seven-day intervals. To conduct the experiment at the age of interest, the length variations of the sample under thermal variations between 5 and $35^{\circ} \mathrm{C}$ were measured using a digital strain gauge. Moreover, in order to remove the shrinkage effect, this temperature variation was applied to the water and the temperature of the sample was changed by altering the temperature of the water surrounding it. Length changes of the sample resulting from temperature variations were recorded and the test was repeated in case of any discrepancy.
After increasing the water temperature, the length of the sample was recorded every 15 minutes. When the length of the sample remained constant, the final number was recorded as the sample length at that temperature. After each test, the samples were placed inside the curing basin until the next experiment. The CTE can be calculated through Eq. (6):

$$
C T E=\frac{1}{L o} \frac{\Delta L}{\Delta \theta},
$$

where $\Delta L$ is the length variation in micrometers, $L O$ the initial length in meters, $\Delta \theta$ the thermal variations in degrees centigrade, and CTE the Coefficient of Thermal Expansion in micro strain per degree centigrade.

\section{Results and discussion}

\subsection{Porosity and compressive strength}

The total porosity of the concrete and paste samples at different ages is shown in Figure 2, based on which it can be concluded that incorporation of silica fume and metakaolin to the concrete would reduce the total porosity of the concrete at all ages more than the reference concrete. On the contrary, while adding slag to the concrete at initial ages increased the total porosity of the concrete, it reduced the porosity at final ages due to pozzolanic reaction. However, the results were different for the pastes. The most substantial difference was observed in the paste containing metakaolin characterized by more porosity at all ages than the reference paste.

The compressive strengths of the concrete and paste samples are demonstrated in Figure 3. According to this figure, the compressive strength of the samples containing silica fume and metakaolin was higher than that of the reference concrete at all ages. In addition,

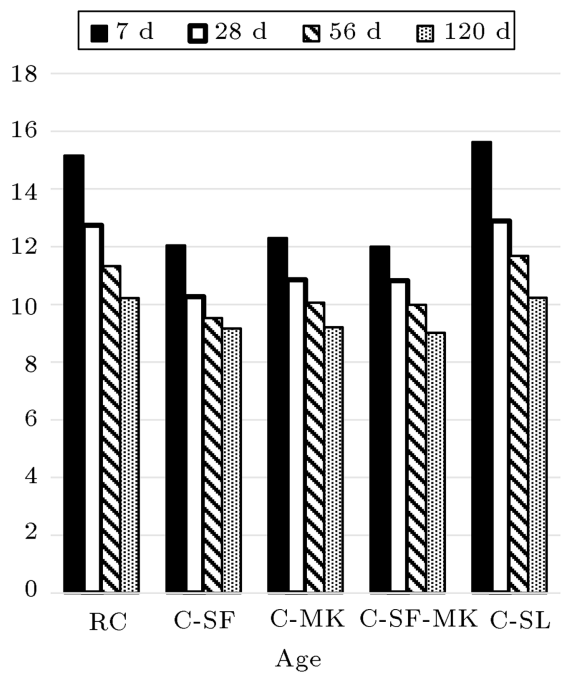

(a)

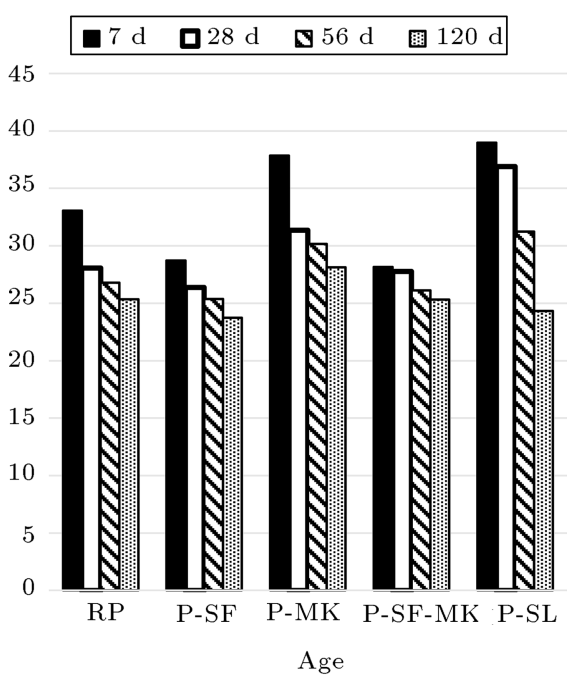

(b)

Figure 2. Change in porosity with the aging of sample: (a) Concrete and (b) paste. 


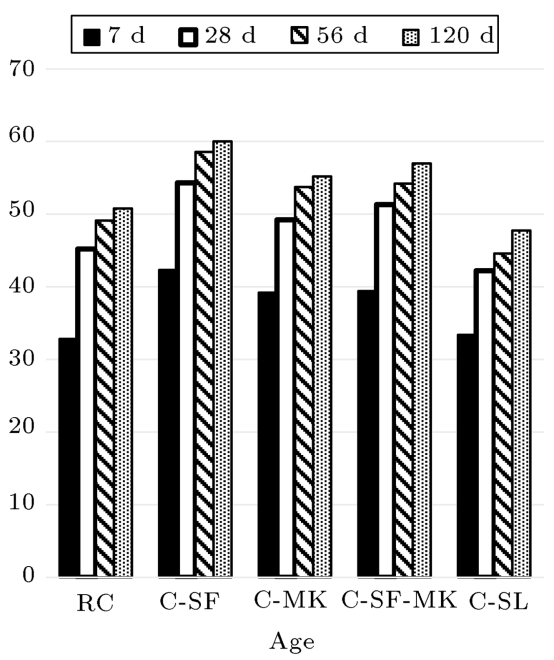

(a)

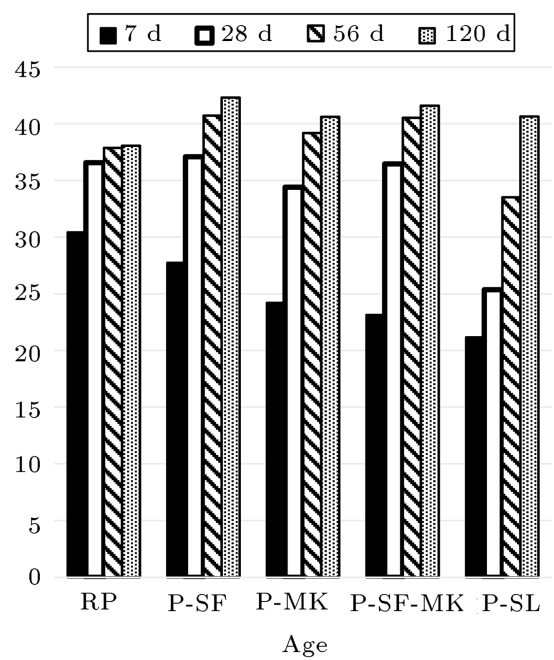

(b)

Figure 3. Change in compressive strength (MPa) with the aging of samples (day): (a) Concrete and (b) paste.

the compressive strength of the concrete containing slag was lower than that of the reference concrete. With regard to the paste, those containing supplementary cementitious materials had less strength than the reference concrete at an early age. However, as the sample aged, its compressive strength grew larger than that of the reference paste, i.e., at final ages, it had greater strength. Meanwhile, the maximum growth of strength was associated with the paste containing slag, which grew by $100 \%$ from 7 to 120 days of age. A comparison of the porosity and compressive strength of the samples showed that reducing the porosity of the concrete samples increased their compressive strength. However, this relationship was not observed for the paste samples. For instance, at the age of seven days, despite its lower porosity, the compressive strength for the sample containing silica fume was less than that of the reference paste. The relationship between the porosity and CTE of the pastes and concrete samples is illustrated in Figure 4. Moreover, the relationship between the paste and concrete in terms of the CTE is shown in Figure 5. In order to better investigate the effects of the CTE of the cement paste and the porosity of the concrete on its CTE, the effects are shown simultaneously in Figure 6. According to this figure, upon increasing the CTE of the paste and porosity of the concrete, the CTE of the concrete would increase.

\subsection{Mercury Intrusion Porosimetry (MIP)}

Table 3 presents the volume of large capillary pores (50-1000 nm), small capillary pores $(10-50 \mathrm{~nm})$, median size of pores (pore size with $50 \%$ cumulative volume), and total volume of pores for the concrete samples. In the concretes containing silica fume and metakaolin, there were some changes in the structure of large and small pores; in other words, while the volume

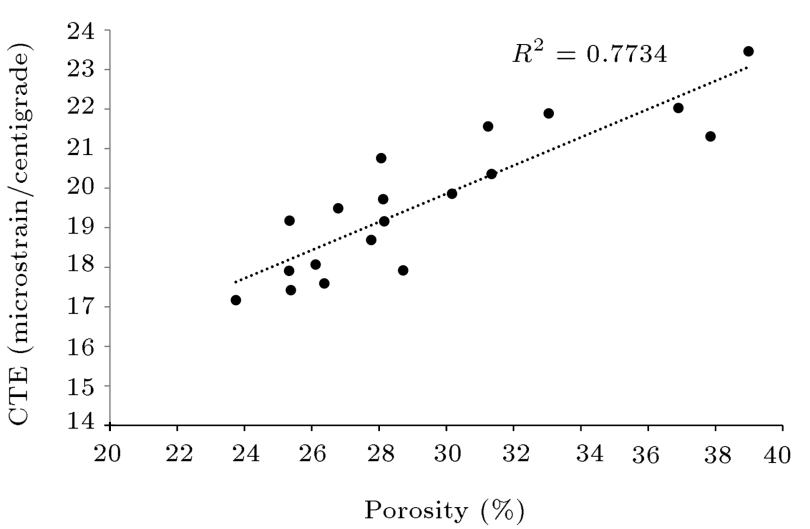

(a)

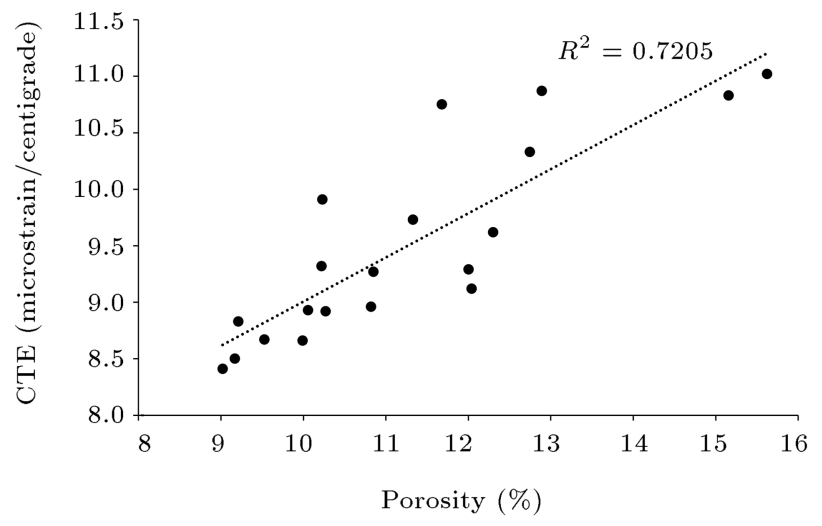

(b)

Figure 4. The relation between porosity and the Coefficient of Thermal Expansion (CTE) of (a) pastes samples and (b) concrete samples.

of the large pores decreased, that of the small pores increased, indicating the decreased diameter of the capillary pores. However, in the concrete containing slag, an inverse trend was observed, i.e., the volume 
Table 3. Result of the pore structure measured by Mercury Intrusion Porosimetry (MIP).

\begin{tabular}{ccccc}
\hline $\begin{array}{c}\text { Specimen } \\
\text { notation }\end{array}$ & $\begin{array}{c}\text { Small pore } \\
\left(\mathbf{m m}^{\mathbf{3}} \mathbf{/ g}\right)\end{array}$ & $\begin{array}{c}\text { Medium pore } \\
\left(\mathbf{m m}^{3} \mathbf{~ g )}\right.\end{array}$ & $\begin{array}{c}\text { Total pore } \\
\left(\mathbf{m m}^{3} \mathbf{~ g}\right)\end{array}$ & $\begin{array}{c}\text { D50 } \\
(\mathbf{n m})\end{array}$ \\
\hline RC & 23 & 45 & 68 & 96 \\
C-SF & 39 & 24 & 63 & 35 \\
C-MK & 35 & 25 & 60 & 31 \\
C-SF-MK & 36 & 25 & 61 & 28 \\
C-SL & 18 & 53 & 71 & 113 \\
\hline
\end{tabular}

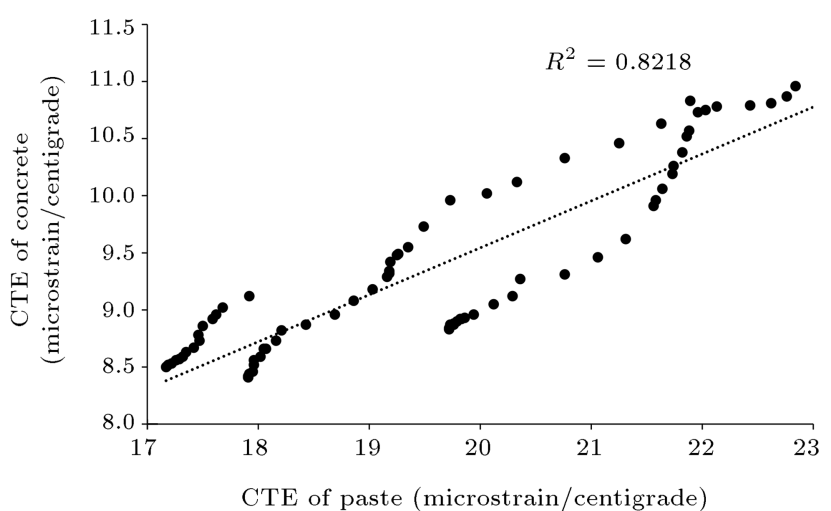

Figure 5. The relation between the Coefficient of Thermal Expansion (CTE) of concrete and that of paste samples.

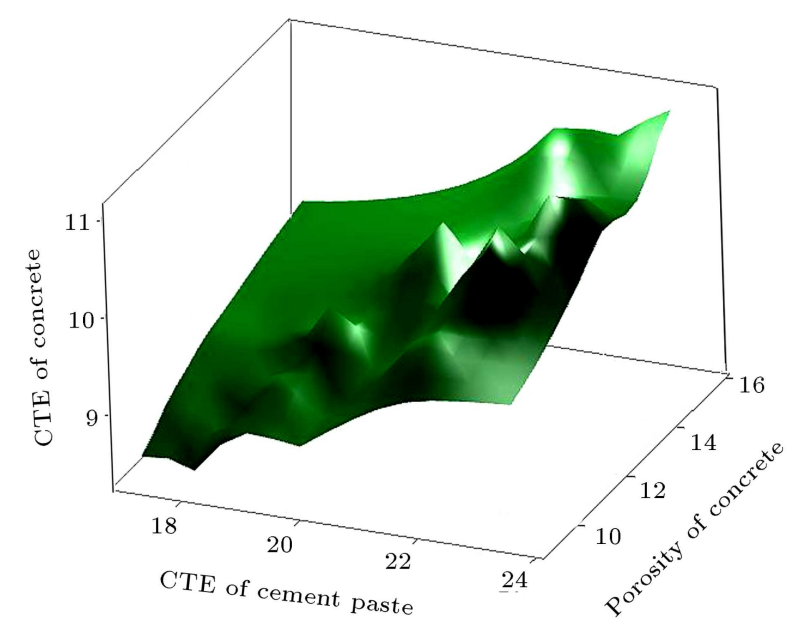

Figure 6. Simultaneous effect of the Coefficient of Thermal Expansion (CTE) of the paste and porosity of concrete on the CTE of concrete.

of the large pores grew more considerably than that of the small pores.

\subsection{The effects of time on CTE}

The CTE changes over time were evaluated based on the CTE of the concrete at seven-day intervals. Figure 7 shows the trend of CTE over time for both concrete and paste. Evidently, with aging of the sample over time, the CTE falls in the concrete and the paste; however, the extent of reduction is different for each

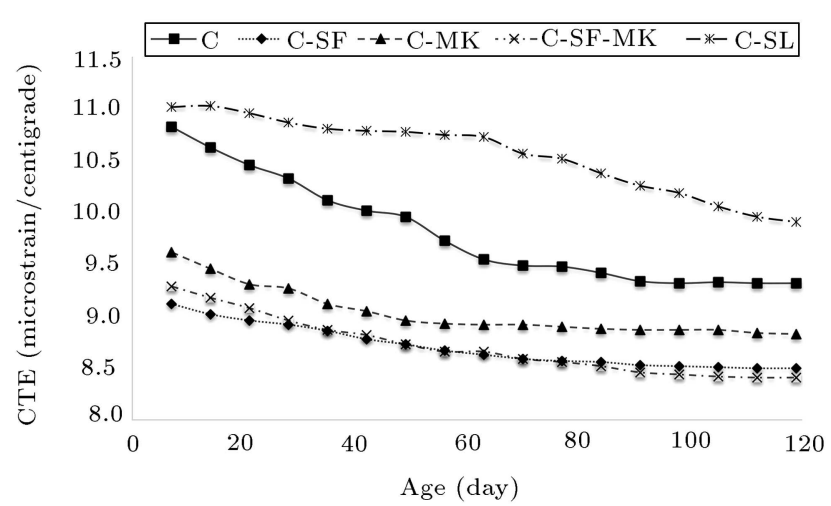

(a)

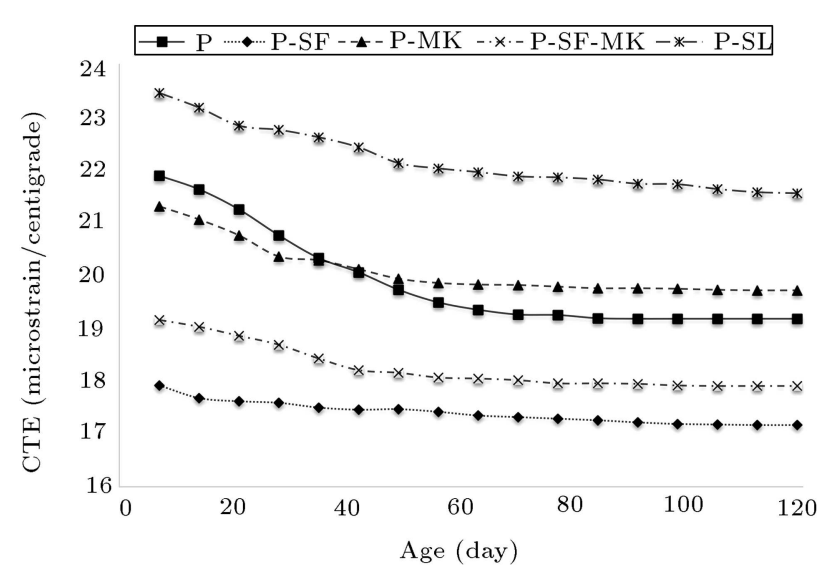

(b)

Figure 7. Change in Coefficient of Thermal Expansion (CTE) with aging of sample: (a) Concrete and (b) paste.

concrete. The concrete containing silica fume and metakaolin had a more favorable condition than the reference concrete and those containing slag at early ages; with the aging of the sample, no significant change occurred in the CTE value. However, for the reference concrete, which initially had no favorable condition, as the sample aged, a significant decline was observed in the CTE; in other words, after 60 days, the CTE was reduced by about $15 \%$. On the contrary, for the concrete containing slag, no significant change was observed up to the age of 60 days. However, after 60 days up to 120 days, the descending slope of the curve increased, dropping by about $10 \%$ up to 120 days. 


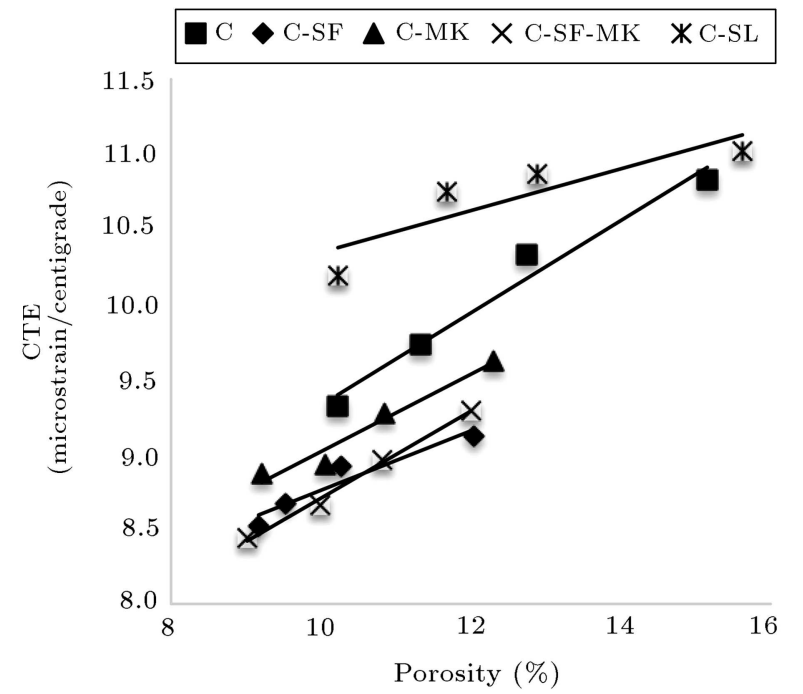

Figure 8. Relationship between the porosity (at various ages including 7, 28, 56, and 120 days) and Coefficient of Thermal Expansion (CTE) of mixtures.

According to Figure 8, the CTE variations of both concrete and paste are different from each other, resulting from different behavior of the aggregates and the existence of a transition zone in the concrete. The CTE of the concrete containing metakaolin was significantly lower than that of the reference concrete at all ages. Moreover, the CTE of the paste containing metakaolin was only slightly lower than that of the reference paste at young ages. However, from the age of 40 days onward, the CTE of the reference paste grew smaller than that of the paste containing metakaolin. Evidently, the presence of metakaolin in the concrete resulted in considerable improvements; however, it failed to generate any improvement in the paste. This can be due to the very positive role of metakaolin in the transition zone and improvement of this region. The CTE values of the concrete and the paste at the ages of 7,56 , and 120 days are presented in Table 4. The Scanning Electron Microscopy (SEM) images of the concrete samples after drying are shown in Figure 9. In this figure, the concretes containing silica fume and metakaolin (C-SF, C-MK, C-SF-MK) are denser than the reference concrete. In the reference concrete, due to the lack of mineral additives, a higher density of $\mathrm{Ca}(\mathrm{OH})_{2}$ is observed. Moreover, the concrete containing slag has less density and more porosity.

Investigation of the CTE and the porosity of the concrete samples revealed that across all samples, the CTE grew upon an increase in the porosity, which was in agreement with Ghabezloo's findings [39]; however, this dependence differed depending on the type of concrete. Evidently, there is no strong relationship between the porosity and CTE of the concrete; in other words, once the porosity is determined, one can estimate the CTE. Further, a comparison between the
Table 4. Result of Coefficient of Thermal Expansion (CTE) of concrete and paste at different ages.

\begin{tabular}{cccc}
\hline & \multicolumn{3}{c}{ Age (day) } \\
\cline { 2 - 4 } Specimen & $\mathbf{7}$ & $\mathbf{5 6}$ & $\mathbf{1 2 0}$ \\
\cline { 2 - 4 } notation & \multicolumn{3}{c}{ Centigrade) } \\
\hline RC & 10.83 & 9.55 & 9.32 \\
C-SF & 9.12 & 8.63 & 8.5 \\
C-MK & 9.62 & 8.92 & 8.83 \\
C-SF-MK & 9.29 & 8.66 & 8.41 \\
C-SL & 11.02 & 10.73 & 9.91 \\
RP & 21.89 & 19.35 & 19.18 \\
P-SF & 17.92 & 17.35 & 17.17 \\
P-MK & 21.31 & 19.83 & 19.72 \\
P-SF-MK & 19.16 & 18.05 & 17.91 \\
P-SL & 23.46 & 21.96 & 21.56 \\
\hline
\end{tabular}

thermal expansion of the concrete and the median diameter of the pores at the age of 28 days revealed that reducing the median diameter of the pores would reduce the CTE of the concrete. Figure 10 depicts this trend where there is a strong relationship between the median diameter of the pores and the CTE of the concrete.

\subsection{Predicting the thermal expansion of the concrete}

4.4.1. Time-dependent model for CTE prediction

Prediction of concrete properties has always been one of the major concerns in civil projects. Accordingly, by using Minitab, curve fitting was applied to the available data so that once the CTE of the concrete at the age of seven days was determined, its CTE was predicted at different ages. As observed, the trend of the CTE over time was different for both reference concrete and those containing supplementary cementitious materials. Accordingly, Eqs. (7) and (8) were formulated for the concrete with and without any supplementary cementitious materials, respectively. In order to evaluate the models, three data points for each concrete were selected as the test data, while the models were trained using the remaining data points (i.e., training data). The test data are shown in Table 5.

$$
\begin{aligned}
& C T E_{t}=1.02 \times C T E_{7}-0.61 \times \operatorname{Ln}\left(\frac{t}{7}\right), \\
& C T E_{t}=1.01 \times C T E_{7}-0.32 \times \operatorname{Ln}\left(\frac{t}{7}\right),
\end{aligned}
$$

where $C T E_{7}$ denotes the CTE at the age of seven days, $t$ represents the age of the sample (day), and $C T E_{t}$ is the CTE at the age of interest. To compare 


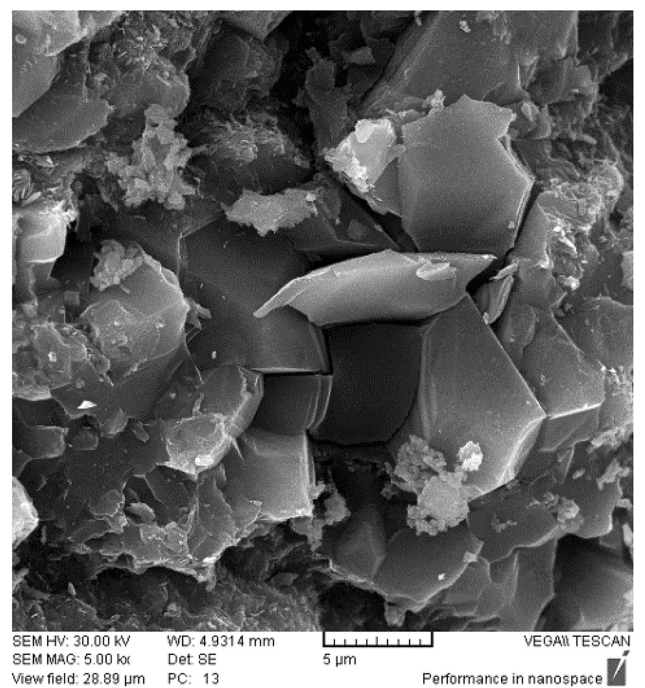

$\begin{array}{ll}\text { SEM MAG: } 5.00 \mathrm{br} & \text { Det SE } \\ \text { View field } 28.89 \mathrm{um} & \text { PC: } 13\end{array}$

$\mathrm{RC}$

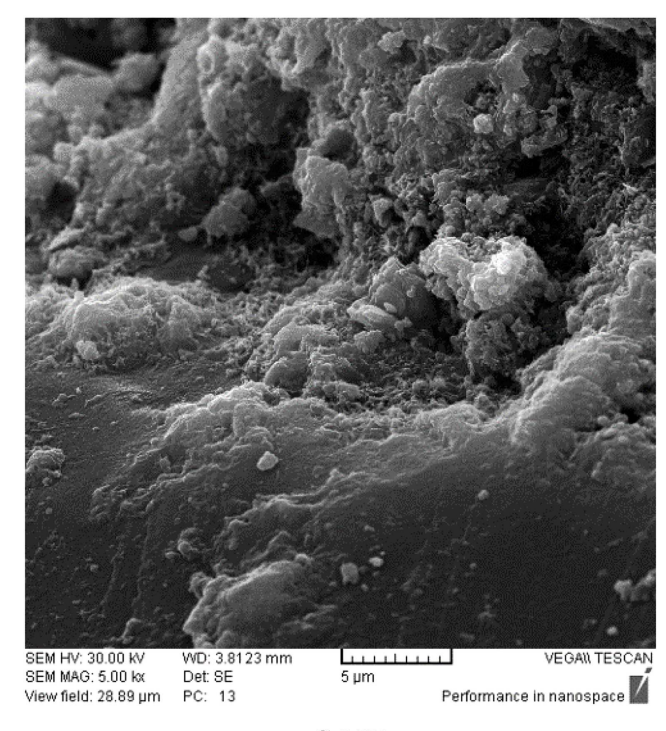

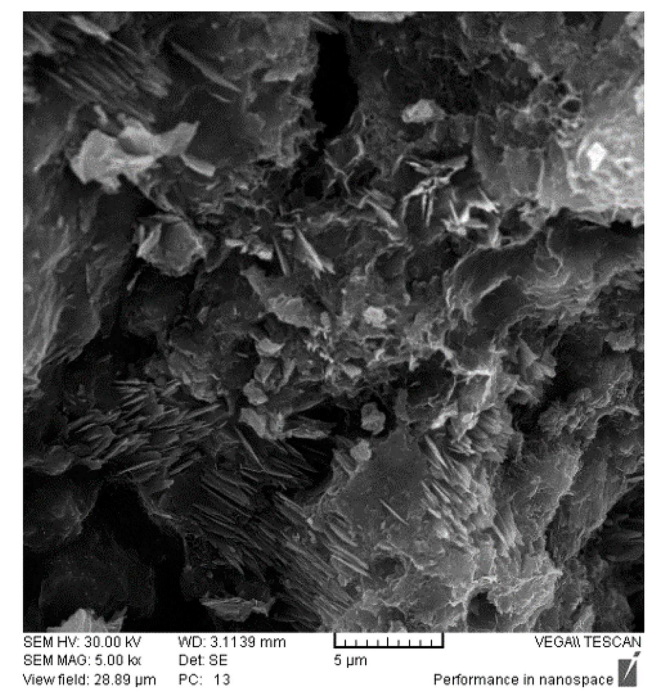

$\mathrm{C}-\mathrm{SF}$

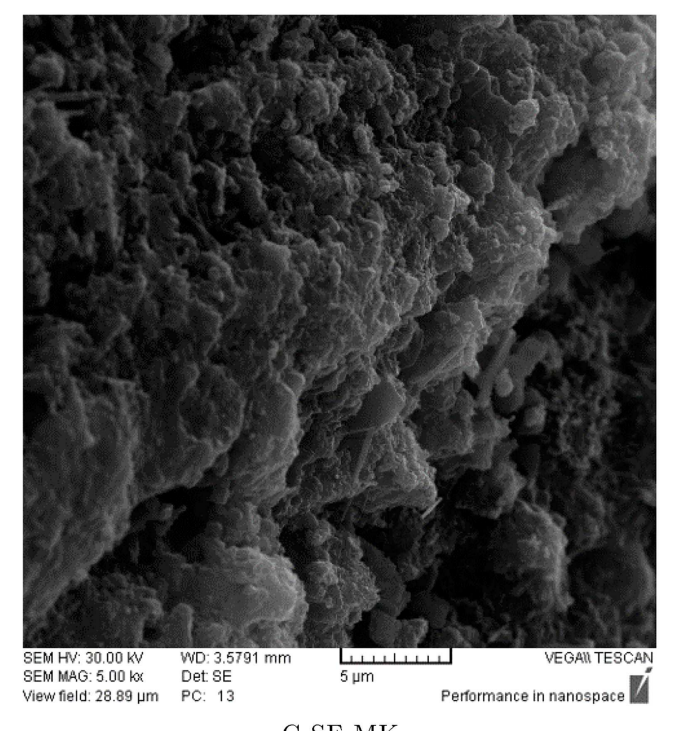

C-SF-MK

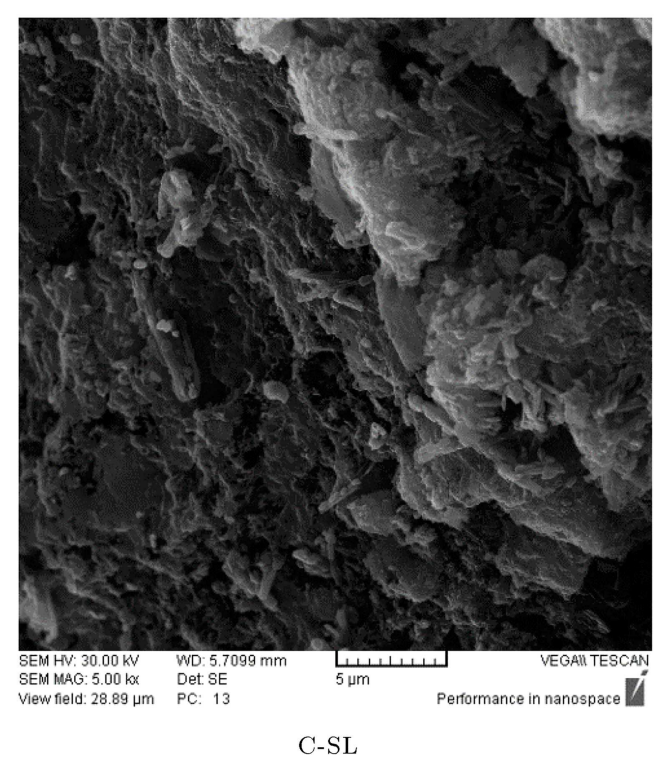

Figure 9. Scanning Electron Microscopy (SEM) images of concrete samples at the age of 28 days. 


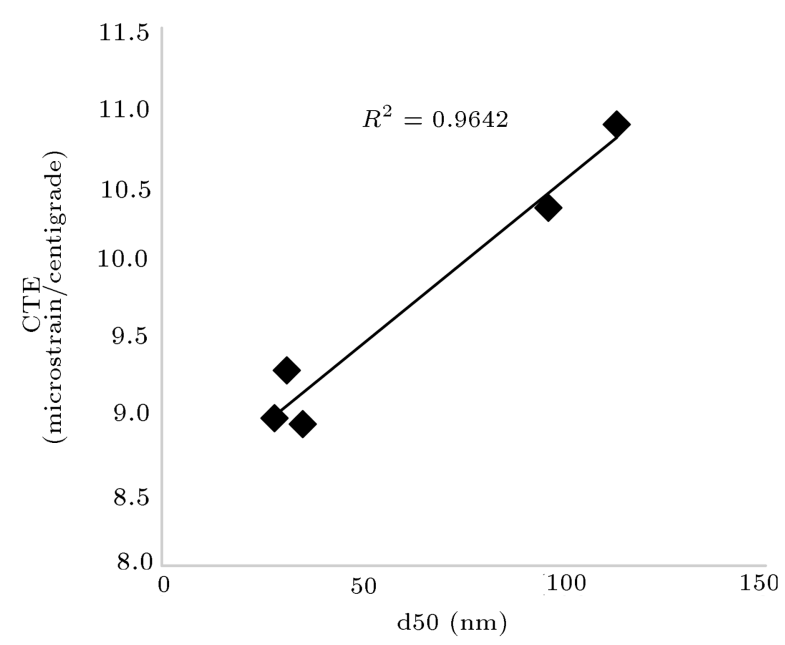

Figure 10. Relation between the median diameter of pores and Coefficient of Thermal Expansion (CTE) of concrete.

Table 5. Test data used for evaluating Eqs. (7) and (8).

\begin{tabular}{cc}
\hline Specimen notation & Age (day) \\
\hline RC & 28 \\
& 77 \\
& 21 \\
C-SF & 42 \\
& 84 \\
& 21 \\
C-MK & 42 \\
& 119 \\
& 28 \\
C-SF-MK & 49 \\
& 91 \\
C-SL & 21 \\
& 70 \\
& 98 \\
\hline
\end{tabular}

the measured CTE through the experiment and the estimated CTE for the test data, these coefficients are plotted in Figure 11. According to this figure, the error of the model is low and the model is highly capable of predicting the CTE of the concrete at different ages.

\subsection{Prediction of CTE Based on packing density values}

The packing densities of the concrete mixtures are shown in Table 6. By replacing the cement with

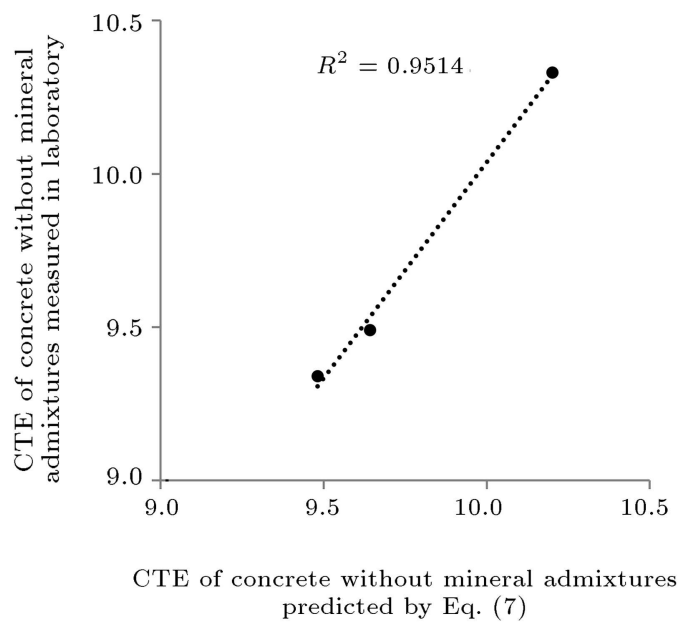

(a)

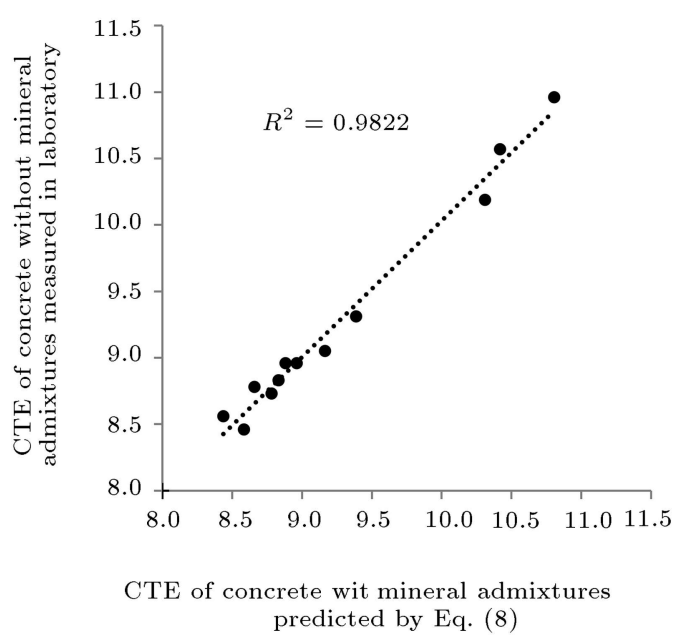

(b)

Figure 11. Comparison of the experimental Coefficient of Thermal Expansion (CTE) of the concrete and the output of Eqs. (7) and (8).

Table 6. Results of the packing density of concrete mixtures.

\begin{tabular}{cc}
\hline Specimen notation & Packing density \\
\hline RC & 0.8212 \\
C-SF & 0.8176 \\
C-MK & 0.8138 \\
C-SF-MK & 0.8113 \\
C-SL & 0.8127 \\
\hline
\end{tabular}

supplementary cementitious materials in the concrete, the packing density would decrease. Ghoddousi et al. [40] attributed this to the loosening effect of using fine-grained particles instead of coarse-grained particles as well as the effects of the wall of coarse-grained particles over the fine-grained ones. In this regard, adding fine-grained particles, such as supplementary 
cementitious materials, to the concrete reduced the packing density.

Since concrete is composed of cement paste and aggregate mixtures, its behavior can be considered as a combination of the behaviors of both paste and aggregate. Accordingly, in order to predict the CTE of the concrete, this study developed a model by combining the CTE of the paste with packing density, as shown in Eq. (9). Based on this model, by measuring the CTE of the paste at the age of seven days and calculating the packing density, the CTE of the concrete can be estimated at the age of seven days. Since the aggregate used in this study is limestone, Eq. (9) is only valid for the concretes made of the limestone aggregate.

$$
C T E_{\text {Concrete }}=7.15 \times \operatorname{Ln}\left(C T E_{\text {Paste }} \times \phi^{8}\right),
$$

where $C T E_{\text {concrete }}$ and $C T E_{\text {paste }}$ are CTEs at the age of 7 days and $\phi$ represents the packing density of the concrete. Figure 12 compares the experimental values and those estimated by the model.

In order to evaluate the model presented in Eq. (9), a sample of the concrete and paste containing $10 \%$ silica fume and $15 \%$ metakaolin was synthesized with the mixing ratio presented in Table 7 . The experimental results were compared with the output results of the model. Of note, the values presented in the table are in $\mathrm{kg} / \mathrm{m}^{3}$. Once the sample was cured and reached the age of seven days, the CTE test was performed on the paste and concrete samples. Then, the CTE value of the concrete obtained from the test was compared with that predicted by Eq. (9), as shown in Table 8. As observed, the model presented based on the packing density and CTE of the paste was highly capable of predicting the CTE of the concrete.

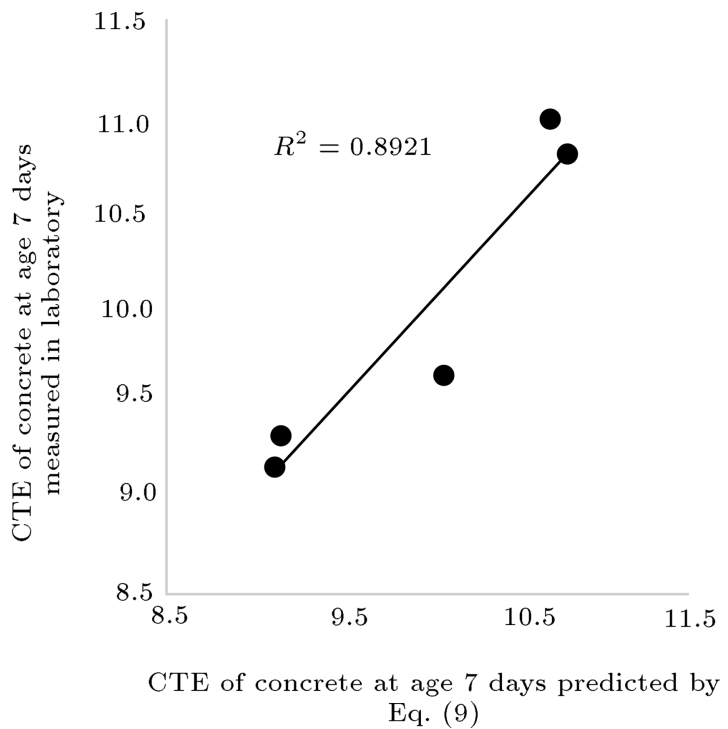

Figure 12. Comparison of the experimental Coefficient of Thermal Expansion (CTE) of the concrete and the output of Eq. (9).

\subsection{Sensitivity analysis of various factors for the CTE of the concrete}

Sensitivity analysis was conducted on the CTE of the concrete in Minitab using the results obtained for the porosity, water absorption, compressive strength of the concretes, and CTE of the cement paste at the ages of $7,28,56$, and 120 days for all mixtures.

In the sensitivity analysis, the $P$-value parameter indicates the effects of different factors on the response. A lower $P$-value shows a stronger relationship between the factor and the response. The $P$-value for all the factors is shown in Table 9.

Given that the $P$-value for the water absorption

Table 7. The mix proportion of concrete used for validating Eq. (9).

\begin{tabular}{cccccccccc}
\hline $\begin{array}{c}\text { Specimen } \\
\text { notation }\end{array}$ & W/C & Binder & Cement & $\begin{array}{c}\text { Silica } \\
\text { fume }\end{array}$ & Metakaolin & Slag & $\begin{array}{c}\text { Course } \\
\text { aggregate }\end{array}$ & $\begin{array}{c}\text { Fine } \\
\text { aggregate }\end{array}$ & $\begin{array}{c}\text { Packing } \\
\text { density }\end{array}$ \\
\hline C-Val & 0.45 & 400 & 300 & 40 & 60 & 0 & 1036.8 & 691.2 & 0.8131 \\
\hline
\end{tabular}

Table 8. Comparing the experimental results with the output of Eq. (9) for the validation sample.

\begin{tabular}{cccccc}
\hline $\begin{array}{c}\text { Specimen } \\
\text { notation }\end{array}$ & $\begin{array}{c}\text { CTE of } \\
\text { cement paste }\end{array}$ & $\begin{array}{c}\text { Packing } \\
\text { density }\end{array}$ & $\begin{array}{c}\text { CTE measured } \\
\text { in laboratory }\end{array}$ & $\begin{array}{c}\text { CTE predicted } \\
\text { by Eq. (9) }\end{array}$ & Error \\
\hline C-Val & 18.86 & 0.8131 & 9.03 & 9.17 & 0.14 \\
\hline
\end{tabular}

Table 9. P-value of different factors for the Coefficient of Thermal Expansion (CTE) of the concrete.

\begin{tabular}{ccc}
\hline Factors & Response & $\boldsymbol{P}$-value \\
\cline { 1 - 1 } Water absorption of concrete & & 0.316 \\
\cline { 1 - 1 } Compressive strength of concrete & & 0.017 \\
\hline CTE of concrete & & 0.025 \\
\cline { 1 - 1 } Porosity of concrete & & 0.015 \\
\hline CTE of cement paste & &
\end{tabular}




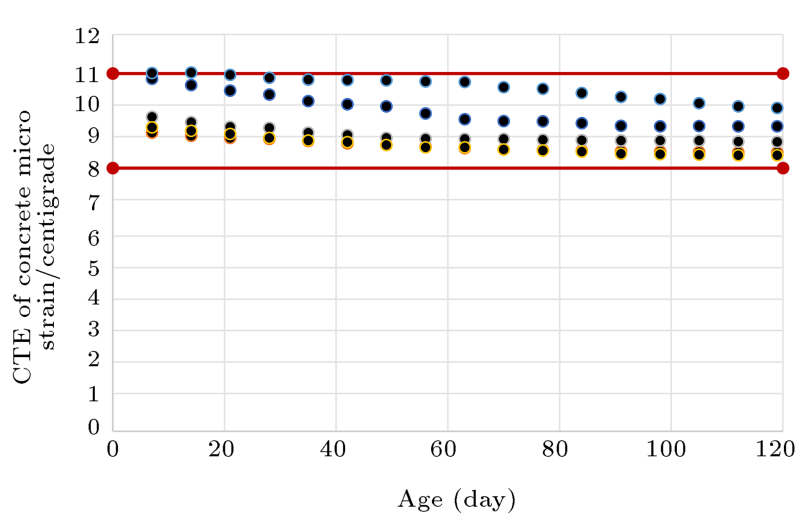

Figure 13. Comparison of the Coefficient of Thermal Expansion (CTE) of all concrete samples with the range of CTE for concrete made with limestone aggregate announced by Bamforth et al. [41].

of the concrete is a large number, this factor does not have a significant effect on the CTE of the concrete.

The lowest $P$-value was obtained for the CTE of the cement paste, indicating its effect on the CTE of the concrete.

According to Bamforth et al. [41] and the results presented in Figure 13, the CTE of the concrete made with limestone aggregate is in the range of 9 microstrain $/{ }^{\circ} \mathrm{C}$. On the contrary, the CTE of all the concretes with any mineral admixtures in all ages is in the range of 9 microstrain $/{ }^{\circ} \mathrm{C}$. It is demonstrated that both CTE of the cement paste and the changes in the cement paste caused by mineral admixtures cannot change the CTE of the concrete. In other words, these parameters do not significantly affect the CTE of the concrete.

\section{Conclusions}

Based on the investigations and tests conducted in this study, the following conclusions are obtained:

- Incorporation of silica fume and metakaolin led to a reduction in the Coefficient of Thermal Expansion (CTE) of the concrete at early ages, compared to the reference concrete. This CTE reduction was mainly due to the reduction in the volume and diameter of the pores inside the concrete. However, incorporating slag increased the CTE of the concrete since it increased the volume of the pores and their structure at the initial ages;

- Over time, the CTE of the reference concrete was reduced by around 1.3 microstrain per degree centigrade up to the age of 60 days. However, for the concretes containing silica fume and metakaolin, only a minor decrease was observed over time. For the concrete containing slag, no change was observed up to the age of 60 days; however, after this age, a considerable descending trend was observed up to the age of 120 days;

- The CTE of the cement paste was about twice as large as that of the concrete, and its changes were different depending on the aging of the sample, hydration reaction, and pozzolanic reaction. The CTE of the paste containing metakaolin was observed to be close to that of the reference paste. However, the CTE of the concrete containing metakaolin was lower than that of the reference concrete, mainly due to the existence of a transition zone in the concrete and the very effective role of metakaolin in this region;

- Across all the concretes, reducing the total porosity of the sample decreased the CTE. Moreover, reducing the diameter of the concrete pores could reduce the CTE again. A strong relationship was observed between the median diameter of the pores and CTE of the concrete.

- Given the dependency of the concrete properties on those of the paste and aggregates, a model was presented by considering the CTE of the paste corresponding to the concrete and packing density to predict the CTE of the concrete. Furthermore, a model was developed to predict the CTE of the concrete at different ages based on the CTE at the age of seven days;

- Among the porosity, water absorption, compressive strength of the concrete, and CTE of the cement paste, the CTE of the cement paste was the parameter that could affect the CTE of the concrete the most. However, these parameters had a negligible effect on the CTE of the concrete because the changes in these parameters could not cause a significant change in the CTE of the concrete.

\section{References}

1. Yang, J. and Kim, S.H. "Factorial effects of mix design variables on the coefficient of thermal expansion of concrete mixtures", Road Materials and Pavement Design, 15(4), pp. 942-952 (2014).

2. Sabih, G. and Tarefder, R.A. "Effects of concrete age on coefficient of thermal expansion of paving mixes and its significance in unbonded overlay design", Journal of Testing and Evaluation, 48(4), pp. 306-318 (2020).

3. Sabih, G., Rahman, T., and Tarefder, R.A. "Quantifying the impact of coefficient of thermal expansion of overlay concrete on unbonded concrete overlay performance", Heliyon, 4(10), e00855 (2018).

4. Sharifi, N.P., Askarinejad, S., and Mahboub, K.C. "Fracture performance of a PCM-Rich concrete pavement under thermal stresses", International Journal of Pavement Engineering, pp. 1-10 (2020). 
5. AASHTO, Standard method of test for coefficient of thermal expansion of hydraulic cement concrete (2000).

6. TI-B 101, Test Method Expansion Coefficient of Concrete, Danish Technological Institute (1994).

7. Zhu, X., Dai, Z., Ling, J., and Chen, L. "Thermal expansion prediction of cement concrete based on a 3D micromechanical model considering interfacial transition zone", Construction and Building Materials, 171, pp. 891-900 (2018).

8. Lukefahr, E. and Du, L. "Coefficients of thermal expansion of concrete with different coarse aggregatesTexas data", Journal of Testing and Evaluation, 38(6), pp. 683-690 (2010).

9. An, J., Kim, S.S., Nam, B.H., and Durham, S.A. "Effect of aggregate mineralogy and concrete microstructure on thermal expansion and strength properties of concrete", Applied Sciences, 7(12), p. 1307 (2017).

10. Won, M. "Improvements of testing procedures for concrete coefficient of thermal expansion", Transportation Research Record, 1919(1), pp. 23-28 (2005).

11. Mateos, A., Harvey, J., Feldman, D.R., Wu, R., Paniagua, J., and Paniagua, F. "Evaluation of the moisture dependence of concrete coefficient of thermal expansion and its impacts on thermal deformations and stresses of concrete pavements", Transportation Research Record, 2674(8), pp. 545-555 (2020).

12. Mateos, A., Harvey, J., Bolander, J., Wu, R., Paniagua, J., and Paniagua, F. "Field evaluation of the impact of environmental conditions on concrete moisturerelated shrinkage and coefficient of thermal expansion", Construction and Building Materials, 225, pp. 348-357 (2019).

13. Wang, H., Mang, H., Yuan, Y., and Pichler, B.L. "Multiscale thermoelastic analysis of the thermal expansion coefficient and of microscopic thermal stresses of mature concrete", Materials, 12(17), p. 2689 (2019).

14. Bažant, Z.P. "Delayed thermal dilatations of cement paste and concrete due to mass transport", Nuclear Engineering and Design, 14(2), pp. 308-318 (1970).

15. Xuan, D.X., Shui, Z.H., and Cao, B.B. "Investigation on thermal deformation divergence between components of cement-basted materials", Journal of Wuhan University of Technology, 29(1), pp. 2-30 (2007).

16. Sellevold, E.J. and Bj申ntegaard, $\phi$. "Coefficient of thermal expansion of cement paste and concrete: Mechanisms of moisture interaction", Materials and Structures, 39(9), pp. 809-815 (2006).

17. Darwin, D., Mindess, S., and Young, J.F., Concrete, Prentice Hall, Upper Saddle River, NJ (2003).

18. Sadrmomtazi, A., Tahmouresi, B., and Kohani Khoshkbijari, R. "Effect of fly ash and silica fume on transition zone, pore structure and permeability of concrete", Magazine of Concrete Research, 70(10), pp. 519-532 (2018).
19. Paiva, H., Silva, A.S., Velosa, A., Cachim, P., and Ferreira, V.M. "Microstructure and hardened state properties on pozzolan-containing concrete", Construction and Building Materials, 140, pp. 374-384 (2017).

20. Saboo, N., Shivhare, S., Kori, K.K., and Chandrappa, A.K. "Effect of fly ash and metakaolin on pervious concrete properties", Construction and Building Materials, 223, pp. 322-328 (2019).

21. Li, Y.X., Chen, Y.M., Wei, J.X., He, X.Y., Zhang, H.T., and Zhang, W.S. "A study on the relationship between porosity of the cement paste with mineral additives and compressive strength of mortar based on this paste", Cement and Concrete Research, 36(9), pp. 1740-1743 (2006).

22. Divsholi, B.S., Lim, T.Y.D., and Teng, S. "Durability properties and microstructure of ground granulated blast furnace slag cement concrete", International Journal of Concrete Structures and Materials, 8(2), pp. 157-164 (2014).

23. Pandey, S.P. and Sharma, R.L. "The influence of mineral additives on the strength and porosity of OPC mortar", Cement and Concrete Research, 30(1), pp. 19-23 (2000).

24. Poon, C.S., Lam, L., Kou, S.C., Wong, Y.L., and Wong, R. "Rate of pozzolanic reaction of metakaolin in high-performance cement pastes", Cement and Concrete Research, 31(9), pp. 1301-1306 (2001).

25. Sullivan, M.S., Chorzepa, M.G., and Durham, S.A. "Characterizing the performance of ternary concrete mixtures involving slag and metakaolin", Infrastructures, 5(2), p. 14 (2020).

26. Tang, F., Li, Z., Tang, Y., Chen, Y., and Li, H.N. "Simultaneous measurement of shrinkage and coefficient of thermal expansion of mortar based on EFPI sensors with nanometer resolution", Measurement, 152, p. 107376 (2020).

27. Shui, Z.H., Zhang, R., Chen, W., and Xuan, D.X. "Effects of mineral admixtures on the thermal expansion properties of hardened cement paste", Construction and Building Materials, 24(9), pp. 1761-1767 (2010).

28. Gao, G.B., Qian, C.X., and Wang, Y.W. "Effect of fly ash and slag powder on coefficient of thermal expansion of concrete", Advanced Materials Research, 374, pp. 1230-1234, Trans Tech Publications Ltd (2012).

29. Alungbe, G.D., Tia, M.A.N.G., and Bloomquist, D.G. "Effect of aggregate, water-cement ratio, and curing on the coefficient of linear thermal expansion of concrete", Journal of the Transportation Research Record, 1335, pp. 44-51 (1992).

30. Bakera, A.T. and Alexander, M.G. "Use of metakaolin as supplementary cementitious material in concrete, with focus on durability properties", RILEM Technical Letters, 4, pp. 89-102 (2019).

31. Duan, P., Shui, Z., Chen, W., and Shen, C. "Effects of metakaolin, silica fume and slag on pore structure, interfacial transition zone and compressive strength of concrete", Construction and Building Materials, 44, pp. 1-6 (2013). 
32. Gonen, T. and Yazicioglu, S. "The influence of mineral admixtures on the short and long-term performance of concrete", Building and Environment, 42(8), pp. 30803085 (2007).

33. Igarashi, S.I., Kawamura, M., and Watanabe, A. "Analysis of cement pastes and mortars by a combination of backscatter-based SEM image analysis and calculations based on the Powers model", Cement and Concrete Composites, 26(8), pp. 977-985 (2004).

34. Poon, C.S., Kou, S.C., and Lam, L. "Compressive strength, chloride diffusivity and pore structure of high performance metakaolin and silica fume concrete", Construction and Building Materials, 20(10), pp. 858865 (2006).

35. Brouwers, H.J.H. "Particle-size distribution and packing fraction of geometric random packings", Physical review E, 74(3), 031309 (2006).

36. Wong, H.H. and Kwan, A.K. "Packing density of cementitious materials: part 1-measurement using a wet packing method", Materials and Structures, 41(4), pp. 689-701 (2008).

37. Standard, A.S.T.M., C188: Standard Test Method for Density of Hydraulic Cement, Annual Book of ASTM Standards (2009).

38. ASTM, C., 642, Standard Test Method for Density, Absorption, and Voids in Hardened Concrete, Annual book of ASTM standards, 4(2) (2006).

39. Ghabezloo, S. "Effect of porosity on the thermal expansion coefficient: A discussion of the paper 'Effects of mineral admixtures on the thermal expansion properties of hardened cement paste' by ZH Shui, R. Zhang, W. Chen, D. Xuan, Constr. Build. Mater. 24 (9)(2010) 1761-1767", Construction and Building Materials, 24(9), pp. 1796-1798 (2010)

40. Ghoddousi, P., Javid, A.S.S., and Sobhani, J. "Effects of particle packing density on the stability and rheology of self-consolidating concrete containing mineral admixtures", Construction and Building Materials, 53, pp. 102-109 (2014).

41. Bamforth, P., Chisholm, D., Gibbs, J., and Harrison, T. "Properties of Concrete for use in Eurocode 2", Blackwater, Camberley, Surrey, UK: The Concrete Center, p. 59 (2008).

\section{Biographies}

Mohammad Ali Etebari Ghasbeh was born in Tehran, Iran in 1994. He received his BSc degree in Civil Engineering from Shahed University in 2016. $\mathrm{He}$ also received the MSc degree in Civil Engineering - Construction Management - at Iran University of Science and Technology (IUST). His research interests include concrete technology, durability of concrete structure, prediction of concrete properties, optimization of concrete mix, project management, and timecost management.

Parviz Ghoddousi is a Professor at Iran University of Science and Technology (IUST). He received his BSc degree in Civil Engineering from Bangalore University, India and his MSc and $\mathrm{PhD}$ degrees in Construction Engineering and Management from University of Leeds, United Kingdom. He is interested in advanced concrete, especially self-consolidating concrete and durability properties of cementitious mixtures.

Ali Akbar Shirzadi Javid is an Assistant Professor at Iran University of Science and Technology (IUST). He received his BSc degree in Civil Engineering from Buali Sina University, Hamedan, Iran and MSc and $\mathrm{PhD}$ degrees in Construction Engineering and Management from IUST, Tehran, Iran. He is interested in concrete technology, especially rheology and durability properties. 